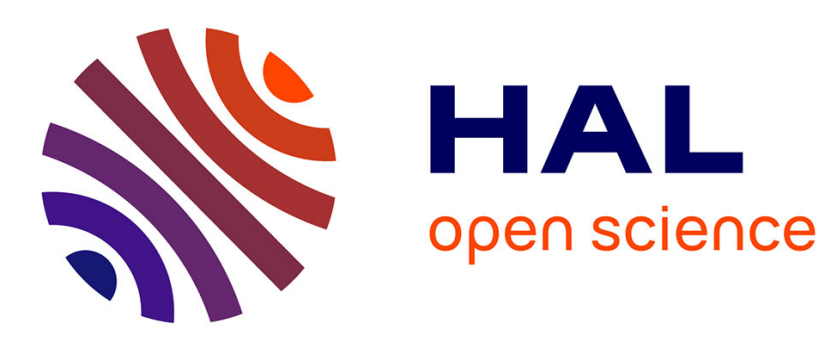

\title{
The Atmospherization of Everyday Experience
}

Jean-Paul Thibaud

\section{To cite this version:}

Jean-Paul Thibaud. The Atmospherization of Everyday Experience. Loenhart, Klaus Klaas. Breathe. Investigations into Our Atmospherically Entangled Future, Basel : Birkhäuser, pp.163-174, 2021, 9783-0356-1210-3. hal-03500321

\section{HAL Id: hal-03500321 \\ https://hal.science/hal-03500321}

Submitted on 22 Dec 2021

HAL is a multi-disciplinary open access archive for the deposit and dissemination of scientific research documents, whether they are published or not. The documents may come from teaching and research institutions in France or abroad, or from public or private research centers.
L'archive ouverte pluridisciplinaire HAL, est destinée au dépôt et à la diffusion de documents scientifiques de niveau recherche, publiés ou non, émanant des établissements d'enseignement et de recherche français ou étrangers, des laboratoires publics ou privés. 


\title{
The Atmospherization of Everyday Experience
}

\author{
Jean-Paul Thibaud \\ to be published In: Klaus K. Loenhart (ed.) \\ breathe! - investigations into our environmentally entangled future. Birkhäuser
}

\section{Towards an atmospheric sensibility}

At a fundamental level, our sensibility towards the spaces in which we live is changing. It is beginning to dawn on us that we do not only inhabit and are inhabited by the earth but also the atmosphere, and that our experience of air and atmosphere has undoubtedly changed over the past centuries (Connor, 2010). We are increasingly observing deliberate strategies to sensorize our everyday surroundings, and to animate living spaces, through light, sound smell, or temperature. All of these entities work on the sensory fabric itself and turn air into a major issue, aiming to install particular climates and explore specific atmospheres and sensorial ambiance. In short, efforts to design ambiance and atmosphere are increasingly adressed and developing the means of profoundly transforming the sensory ecology of lived space.

On the other hand, the sensory discourse increasingly lends itself to scientific approaches and positions. From sensory to material culture studies, through sonic studies and affect theory, a complex body of work is taking a fresh look at the frameworks of experience. Rather than talking about the quality of life or well-being in a general way, theoretical and conceptual tools of comfort are being refined. People are taking an interest in notions of embodiment and attunement, immersive phenomena and affective tuning, ambiant effects and climatic envelopes, quasi-things (Griffero, 2017) and phenomena such as hyper-objects (Morton, 2013). All these approaches are expressing interest in the sensory, and mapping out original lines of inquiry for a theory of ambiances. New vistas are opening up for research, the aim being to account for the shifts in our socio-aesthetic relation to the environments in which we are intertwined.

As Félix Guattari so rightly pointed out (1992: 141) 'The aesthetic power of feeling, although equal in principle with the other powers of thinking philosophically, knowing scientifically, acting politically, seems on the verge of occupying a privileged position within the collective assemblages of enunciation of our era.' It is essential to understand that for this rejuvenated aesthetic what matters most is feeling and sensing (Böhme, 2016): flows, tonalities, atmospheres, affects and other vectors of the intensity of experience, which are now taking over from a world consisting exclusively of objects and substances. With an orientation of this sort, ontology itself is called into question, its focus shifting now to immaterials (Lyotard, 1985), striving to approach the incorporeal (Cauquelin, 2006) and the aesthetic of the ephemeral (Buci-Glucksmann, 2003). This new aesthetic paradigm, advocated by Guattari as the basis for his ecosophy, is central to the current debate in urban studies. Rightly so, for the urban environment operates as an excellent soundingboard for tonalities and contemporary atmospherization phenomena. It also offers a unique laboratory for revealing new ways of feeling, challenging established frameworks of thought, and experimenting new methods of inquiry.

In this respect, the notion of ambiance provides a perspective particularly well suited to investigate the field of ordinary experience and everyday situations (Thibaud, 2015). It enables us to focus our attention on the atmospheric nuances of life, but it only effectively exists in relation to specific, singular contexts. It would certainly be a mistake to separate 
the sensory from the conditions which inform it and the processes which transform it. Ambiance postulates a sensorium grounded in territories and materialities, narratives and habits, climates and seasonalities, normative expectations and background affects. When turning towards the making of atmospheres we must be sensitive to the complex assemblage, diverse elements and force lines running through a situation. In this sense an ambiance is an elementary format from which the atmospheric emerges and opening itself to experience.

We have reached a historic point with the topos and transformation of the sensory conditions of our existence. With his spherology, Peter Sloterdijk describes in great detail this process of explicitation which contributes 'to elevating the atmospheric to the rank of a theory' (Sloterdijk, 2005: 30). In short, atmospheric sensibility really is re-emerging and making itself heard, and ambiance is one of its most powerful loud-hailers.

\section{About cultivated airs}

If efforts are made to design the ambiance of space we may reasonably assume they entail the conditioning of air playing on a wide range of scales, issues and contexts. Moreover, one of the questions this process raises is the connection between 'Air' in the singular - a homogeneous, undifferentiated medium essential to living organisms - and cultivated airs in the plural - specific atmospheric situations that set their mark on sensory spaces. From the stifling smog of congested megacities to the artificial atmosphere of a postmodern shopping mall, air is intimately involved in a whole range of societal devices, ranging from micro to macro. The transformation of inhabited territories may involve deploying specific atmospheres, controlled climates and other forms of modified air, but it nevertheless depends on the existence of air in many different forms and on our ability to experience the air in many ways. Touching on air we are immersed in a transversive field which plays on all the senses and all the registers of spatial life. As a tentative proposition, without in any way claiming to be exhaustive, we may draw a distinction between air as weather, subnature, commodity and the ambient.

Let's start with weather! Wind, rain, sunshine, snow, mist and heat waves: all sorts of weather conditions are examined from the angle of a history of sensibility (Corbin, 2013), of meteorological culture (Ethnologie Française, 2009), urban (Jankovic, 2013) or cultural climatology (Thornes, 2008). While numerous devices seek to neutralize our perception of the weather in producing invariably temperate and shielded environments, our sensibility to climate is in fact growing more acute. Moreover, it is the nature of our sensibility itself which is at stake here, as Tim Ingold explains. 'As the weather changes, so these capacities vary, leading us not to perceive different things, but to perceive the same things differently. (Ingold, 2011: 130). At stake here is the way we design a world with atmospheres, how we experience and inhabit them. In this respect our environment is not a composite object comprising closed, hermetic spaces, but a place very much exposed to the seasons and the prevailing weather, to climatic variations and meteorological shifts, in short to conditions of relative impermanence (Saito, 2004). This interest in weather should remind us that air is constantly circulating and modulating, slipping into crannies and gaining fresh momentum. It is an incentive to replace the immutable, fixed forms of built environments with a rationale fed by streams in motion and changing phenomena. After striving to develop conditioned surroundings and environmental technologies (Benham, 1969), architecture is once more realising that a space must breathe, much as its occupants. Following the vernacular air-conditioning systems (Ramos and Ramos Sanz, 2006), it is now entering a truly meteorological approach, in search of fluctuating atmospheres, fluid spaces and permeable membranes, engaged in dialogue with the seasons and climatic situations (Rahm, 2009). The air involved in weather is thus bringing about an ecology of infiltration, fluctuation and modulation. 
Let's turn to subnature next. At a specifically urban level, we need to understand how urban environments play its part in our experience of the weather, how it modulates the latter, be it in terms of air-flow and quality, radiation, moisture and rainfall (Jankovic and Hebbert, 2012). Urban environments are not merely subjected to the climate, it is one of its players too. This cultural formatting of climate and the emergence of culturally induced microclimates has given rise to the topic of subnature (Gissen, 2009), with a focus on problematic atmospheric conditions dominated by noxious gases and foul smells, toxic fogs and unbreathable smoke. While such conditions may of course result from disasters or temporary catastrophes, it should not distract us from the ongoing, large-scale degradation of the atmospheric conditions in which we live. As Alexis Zimmer has shown (2016), breathing toxic air is an ordinary feature of our era. We can observe processes of an ecology of contamination. While obviously such a trend ask for countering it, our societies also need to review and evaluate the social and political stakes. It is not only a matter of acknowledging the vital dimension of air but also of knowing who breathes what, how and where. Nor can there be any doubt as to the existence of atmospheric inequality particularly apparent in megacities - part and parcel of a geopolitics of verticality, leading to a logic of security and contributing to strategies of exclusion (Adey, 2013). In short, the conditions of urban air confirm, all the way down the line, a political ecology, reflecting a societal separation of the sensory.

Let us move one step further. Attempts to consciously comodify air relates more directly to the process of aestheticizing urban space. Lodged in the experience economy (Pine and Gilmore, 1999), urban atmospheres are increasingly heavily loaded, deliberately planned and deployed, in some cases even serving specific strategies. Such atmospheres can thus be seen in carefully designed lighting and spectacular light shows, it can be heard in soundscapes and day-long musical backdrops, indeed it can even be smelt in experimental odorization and artificial climate-control. Backed by operations to embellish, decorate or commercialize lived spaces, these ambiant devices set the tone for a commodified atmosphere. They instil certain motor and affective dispositions in the body, while revealing the atmospheric skin of the city (Griffero, 2013). It is possible that such ambiant aestheticization heralds the emergence of an ambiance designed to act as a showcase for a flattering brand image keen to display an attractive environment. In this case ambiance is a domain to be exhibited and capitalized on, as such. It is part of an ecology of seduction that fits into an economy of affects, tending to replace an exclusive rationale with its inclusive counterpart (Allen, 2006). Clearly the notion of atmosphere itself now connects to socioeconomic stakes vital to the formulation of the cultural realm, acting as a key word in cultural governance (Hasse, 2014).

The ambient, as invisible and formless air finally becomes the medium of 'augmented' perception and connected subjects. As such it relates to the electromagnetic field that enables the transmission of messages. New sensory relations are being experimented with the milieu(s) in which we live, bearing on ubiquitous, pervasive data-streams passing through the embedded experience of users. At the same time this trend raises the key question of attention, associated with the lower cognitive load and higher tacit know-how associated with the use of new technology (McCullough, 2013). If there is such a thing as ambient intelligence, it must be as integrated as possible, entailing effort and deliberation, based on implicit processes of accustomation and incorporation. Connected sensibility acts to raise attention to stimulate the sense of flow. This is the focus of an ecology of attention (Citton, 2014), looking at new ways of paying attention to our surroundings. It seeks to describe the devices for catching, directing and organizing attention, without overlooking peripheral, distributed perceptions. The scale of this technological instrumentation is such that it impacts both the world of trade and consumption, surveillance and weapons, art and 
creative endeavour (Crang and Graham, 2007). Quite clearly all aspects of cultural life are now affected by the growing impact of the digital world.

\section{An ecology of mixture}

To make atmospherization of the everyday experience even more explicit and connect up the various ecologies it brings into play, it is important to understand that ambiance is not just one sensory domain among others, but rather the one by which the world becomes perceptible, the one that makes the sensory exist (Coccia, 2010). Rather than presenting itself as an object of perception - as might be the case for a live show or even a landscape - ambiance only emerges subject to the condition of perception itself. As a sensory medium (Böhme, 1992), or rather intermedium, ambiance is what makes perception possible, starting from what we perceive. In other words we do not perceive ambiance properly speaking, we perceive according to it. In this respect air is certainly the medium par excellence, 'the medium through and in which everything may appear' (Irigaray, 1983: 41).

This is an important point, prompting for a review of our thinking on ecology and highlighting the need to clarify what the world is made of. With our emphasis on flows, radiation and other atmospheric phenomena, we place ourselves firmly on the side of the elemental (Macauley, 2009) and the flesh of the world (Merleau-Ponty, 1964). From this perspective we are not in the world, but well and truly of the world, made of the same stuff and with the same texture as the world. Merleau-Ponty used a variety of words in reference to this embrace: not a face-to-face relation, or even one of inclusion, rather one of intertwining, enveloping and embedding.

The body is thus so porous to its surroundings, so permeable - think of the air we breathe or the sound that resonates within us, the odour or heat which invades us - that there is no justification for the dichotomy between subject and object. With atmospheres, we need on the contrary to learn to think in terms of quasi-things without edges or surfaces, coming and going intermittently (Griffero, 2017). Resonating with pre-Socratic Ionian philosophy, ambiance calls into question an ontology of the object, preferring to focus on an ontology of the elemental, at the very root of sensing and conceptualizing our relation to the world (Barbaras, 1998). This ambiant ecology, sensitive to gaseous states, fluid spaces and aerial vibrations is almost certainly best expressed in breath, the dual movement of breathing in and out, which translates our fundamental permeability to the world around us. Drawing on sensitive observation of plant life, Emanuele Coccia makes breath the ultimate paradigm for embodiment, a perfect illustration of our truly atmospheric condition. 'We do not inhabit the earth, we inhabit the air by way of the atmosphere. We are immersed in it exactly like a fish is immersed in the sea,' (Coccia, 2016: 81). This is surely a call to acknowledge that the world has the consistence of an atmosphere, to re-affirm the compenetration of beings and milieus, ultimately leading to a metaphysics of mixture, which in turn requires us to highlight the practical consequences.

Addressing ecology in the light of ambiance also enables us to question the big divide between nature and culture, between physical entities and the life of the intellect. We may thus find use for Alfred Whitehead's critique of the bifurcation of nature (1920). After all, elements as diverse as air, water, ground or plants are as much factors of ambiance and environmental resources. They play a part in our sensory experience while nourishing our habitat. In other words, the elements enable us to conceptualize the inextricable, intrinsic link between what is felt and what is vital, between what makes us feel and what makes life possible. Focusing on atmosphere, it is impossible to dissociate its meteorological side from its affective side (McCormack, 2008; Ingold, 2012), its climatic side (gaseous envelope) from its aesthetic side (affective tonality). It reveals to us that the unity of the world is neither physical nor spiritual, but rather medial in nature. 


\section{Taxonomized atmospherization}

How then do things engage with the processes of atmospherizing place and space? Is it possible to identify several modus operandi which take account of the ecology of mixture and can be deployed as closely as possible to daily life? In order to explore such questions I propose to open a provisional lexicon, comprising seven terms, which resonate with one another and each highlight a particular side of atmospheric conditioning (pervasiveness, pregnancy, protection, attachment, self-evidence, vitality and trust). In a way, the aim is to initiate a vocabulary that seeks to break free from an overly substantialist conception and come as close as possible to the precarious, ephemeral and evanescent existence of atmospheric situations.

- Defocusing makes us available to outlines and envelopes. Rather than concentrating on a particular aspect or ingredient of a situation, this process requires us to pay attention to everything going on between and around it, to recognize the existence of the margins, interstices and fringes of experience and fields of perception. In this respect a more subtle way of perception and drifting attention play an essential part to unfold atmosphere's mode of existence (Pallasmaa, 2014).

- Impregnation relates to an atmosphere's discreet, pervasive and lasting mode of influence, to a phenomenon of infusing which persists in time and generally acts imperceptibly and infinitesimally (Thibaud, 2017). It highlights the climatic pregnancy of a setting and enables us to emphasize our dual ability to inhabit the world and be inhabited by it. Impregnation designates the modus operandi by which an ambiance actualizes its immersive power.

- Air-conditioning is an artificial process involving the design of technical devices and spaces protected from the outside air, generally resulting in the production of a temperate, homogeneous and invariable environment. In its most radical version air-conditioning has been enlisted in the capsularization of urban spaces (De Cauter, 2004). More broadly it refers to the operation by which a society conditions the air making up its living environment.

- Tonalization is the operation that activates our environmental sensibility, our power to be affected and let our imagination join in (Bachelard, 1948). It brings into play our propensity for resonating and sympathizing with the ambiant world, which explains why urban atmospheres are always loaded with affective tonalities and evocative images. In this way the world assumes an emotional value and a force of attachment.

- Defamiliarization is a process that originated in the art world. It involves making strange a familiar object we usually take for granted (Chklovsky, 2008 [1923]). Passing unnoticed most of the time the air's existence is made manifest by art installations and acts which heighten or upset ordinary experience. Experiments of this sort enable us to sense the often imperceptible nature of climatic phenomena (Knebusch, 2008).

- Animation involves breathing life into a setting and making us feel vitality affects (Stern, 2010). By lending themselves to all sorts of draughts, aeraulic flows, a large variety of breezes, puffs and other gusts-atmospheres activate dynamic phenomena of varying scale. This relates to the energy in air, its capacity to stimulate basic sensory-motor schemas and sustain a certain tonicity in our living environment.

- Installation refers to the operation starting from which an atmosphere takes hold locally, more or less durably. Installing an atmosphere means both taking and giving place, fitting into a place and transforming it, adjusting to a situation and activating it (Thibaud, 2014). Installation may take the form of a sudden, one-off event, or on the contrary bring into play an unobtrusive, long-term process.

These various operations lead us to pay attention to the field of the infra-sensible. Opening up the world to its ambiant content and atmospheric variations prompts us to consider the 
subtlest features of experience. Ambiance filters the perceptible and the imperceptible, distributes usual and unusual sensations, maps out our perceptual blind spots and plays a key part in sharing out the sensory. In short, if transformation of our sensibility can be identified, then we should be able to find traces of it in the ambiances which inhabit us from day to day. As shown, ambiance relates to the pathic basis of experience (Tellenbach, 1968), brings into play our sense of nuance and our sensibility to small perceptions, setting the tone of our most ordinary acts and gestures. It may be likened to what François Bonnet calls the 'infra-world', 'the setting of non-objectivated sensations, of unconscious impressions, events barely noticed or not sufficiently to be recalled' (Bonnet, 2015: 72). Some modes of atmospherization may be particularly noticeable, operating on a large scale, but others work their way on the same level as low-intensity phenomena and micro-events, on the margins of perception, in the molecular domain of hyper-sensibility, which broadens the scope of our perceptions (Grossman, 2017).

\section{Ecology at home}

The realization that we have entered the Anthropocene opens the way for a renewed sensory ecology, more aware of the ambiant, climatic, sensory, affective and existential conditions of ordinary experience. What is at issue is not just our forms of perception, but more broadly the modes of atmospherizing the world and the ontological dimension underpinning them (Courtright, 2013). Ambiance is contributing to profoundly rethink our attachment to the world, enabling us to consolidate a non-instrumental approach to nature and fuelling the development of an ecological socio-aesthetic. It may even be the case that focusing attention on ambiances may help us to learn how to listen to the Earth (Abram, 1997) and bring ecology at home (Di Chiro, 2014). The quality of breezes, intensity of flows, fluidity of mixtures and pregnancy of climates play a fundamental part in the everyday vibrancy of lived spaces. From this point of view ambiance calls into question the idea of a possible exteriority of nature and enables us to check in concrete ways that we truly are embedded. By enabling each and everyone to feel that they belong in this world, it helps us conceptualize the conditions for an integrating ecological thought in even the humblest and ordinary situations.

By sharpening our perception to notice micro-perceptions and nuances of experience, vitality affects and powers of agency, ambiance in some sense guides our attention: attention to the pervasive feelings of vulnerability that the urban environment may stir, to the feelings of estrangement from a world we struggle to recognize, to low-intensity phenomena which make our space liveable and welcoming. The forms taken by everyday life could relate to our manner of being sensible to the spaces we inhabit and our ability to express our consideration in almost imperceptible ways.

Beyond doubt, ambiance is much the same as a common good that we may nurture or degrade, abuse or take care of. By taking an interest in processes of atmospherizing the world we can actually test the most precarious, fragile side of our existence.

\section{Bibliography}

ABRAM, David (1997) The Spell of the Sensuous: Perception and Language in a More-than-Human World. New York, Vintage Books.

ADEY, Peter (2013) Air/Atmospheres of the Megacity. Theory, Culture \& Society. Vol. 30, n7/8, p. 291-308.

ALLEN, John (2006) Ambient power: Berlin's Potsdamer Platz and the seductive logic of public spaces. Urban Studies. Vol. 43, n², p. 441-455.

BENHAM, Reyner (1969) The Architecture of Well-Tempered Environment. Chicago, The University of Chicago Press.

BARBARAS, Renaud (1998) Le tournant de l'expérience. Paris, Vrin. 
BÖHME, Gernot (1992) An Aesthetic Theory of Nature: An Interim Report. Thesis Eleven, n³2, p. 90-102. BÖHME, Gernot (2016) The Aesthetics of Atmospheres. New York, Routledge.

BONNET, François J. (2015) L'infra-monde. Editions MF.

BUCI-GLUCKSMANN, Christine (2003) Esthétique de l'éphémère. Paris, Éditions Galilée.

CAUQUELIN, Anne (2006) Fréquenter les incorporels. Contribution à une théorie de l'art contemporain. Paris, PUF.

CHKLOVSKI, Victor (2008) [1923] L'Art comme procédé. Arles, Editions Allia.

CITTON, Yves (2014) Pour une écologie de l'attention. Paris, Seuil.

COCCIA, Emanuele (2010) La vie sensible. Paris, Payot.

CONNOR, Steven (2010) The Matter of Air. Science and Art of the Ethereal. London, Reaktion books.

CORBIN, Alain (2013) (dir.) La pluie, le soleil et le vent. Une histoire de la sensibilité au temps qu'il fait. Paris, Aubier.

COURTRIGHT, Jeffrey M. (2013) Is Trust Like an 'Atmosphere'? Understanding the Phenomenon of Existential Trust. Journal for Philosophy in the Contemporary World. Vol 20, n¹, p. 39-51.

DE CAUTER, Lieven (2004) The Capsular Civilization. Rotterdam: NAi Publishers.

CRANG, Mike \& GRAHAM, Stephen (2007) Sentient cities : ambient intelligence and the politics of urban space. Information, communication society. 10 (6). p. 789-817.

DI CHIRO, Giovanna (2014) Ramener l'écologie à la maison. In HACHE, Emilie (Ed.) De l'univers clos au monde fini. Éditions Dehors. p. 191-220.

ETHNOLOGIE FRANÇAISE (2009) Météo. Du climat et des hommes. Tome XXXIX, nº 4, PUF.

GISSEN, David (2009) Subnature. Architectures's other environments. New York, Princeton Architecture Press.

GRIFFERO, Tonino (2013) The atmospheric "skin" of the city. Ambiances. Sensory [Online], http://ambiances.revues.org/399.

GRIFFERO, Tonino (2017) Quasi-Things. The Paradigm of Atmospheres. Albany, Suny Press.

GROSSMAN, Evelyne (2017) Eloge de l'hypersensible. Paris, Éditions de Minuit.

GUATTARI, Félix (1992) Chaosmose. Paris, Galilée.

HASSE, Jürgen (2014) Atmospheres as Expressions of Medial Power. Understanding atmospheres in urban governance and under self-guidance. Lebenswelt. 4.1, p. 214-229.

INGOLD, Tim (2011) Being alive. Essays on movement, knowledge and description. New York, Routledge.

INGOLD, Tim (2012) The Atmosphere. Chiasmi International. vol. 14, p. 75-87.

IRIGARAY, Luce (1983) L'oubli de l'air. Paris, Éditions de Minuit.

JANKOVIĆ, Vladimir \& HEBBERT, Michael (2012) Hidden climate change - urban meteorology and the scales of real weather. Climatic Change. 113 (1), p. 23-33.

JANKOVIĆ, Vladimir (2013) A historical review of urban climatology and the atmospheres of the industrialized world. WIREs Climate Change. Vol. 4, Issue 6, p. 539-553.

KNEBUSCH, Julian (2008) Art and Climate (Change) Perception: Outline of a Phenomenology of Climate Change. In KAGAN, Sacha \& KIRCHBERG, Volker (Eds.) Sustainability: A New Frontier for the Arts and Cultures. Frankfurt a. Main: Verlag für Akademische Schriften p. 242-262.

LYOTARD, Jean-François (collectif) (1985) Les Immatériaux. Paris, Centre Georges-Pompidou.

MACAULEY, David (2010) Elemental philosophy. Earth, air, fire and water as environmental ideas. Albany, State University of New York Press.

McCORMACK, Derek (2008) Engineering affective atmospheres on the moving geographies of the 1897 Andrée expedition. Cultural Geographies. 15(4), p. 413-430.

McCUllougH, Malcom (2013) Ambient Commons. Attention in the Age of Embodied Information. Cambridge, The MIT Press.

MERLEAU-PONTY, Maurice (1964) Le Visible et l'invisible. Paris, Gallimard.

MORTON, Timothy (2013) Hyperobjects: Philosophy and Ecology After the End of the World. Minneapolis, University of Minnesota Press.

PALLASMAA, Juhani (2014) Space, place and atmosphere. Emotion and peripherical perception in architectural experience. Lebenswelt. Aesthetics and philosophy of experience. 4, p. 230-245.

PINE, Joseph \& GILMORE, James (1999) The Experience Economy. Boston, Harvard Business School Press.

RAHM, Philippe (2009) Architecture météorologique. Paris, Archibooks + Sautereau Éditeur.

RAMOS, Fernando \& RAMOS SANZ, Anna (2006) Rafraîchissement. Systèmes vernaculaires de climatisation. Faces. Journal d'architecture. n 63 , p. 24-27. 
SAITO, Yuriko (2004) The Aesthetics of Weather. In LIGHT, Andrew \& SMITH, Jonathan (eds.) The Aesthetics of Everday Life. New York, Columbia University Press. p. 156-176.

SLOTERDIJK, Peter (2005) Ecumes. Sphères III. Paris, Maren Sell Éditions.

STERN, Daniel (2010) Les formes de vitalité. Psychologie, arts, psychothérapie et développement de l'enfant. Paris, Odile Jacob.

TELLENBACH, Hubertus (1983) Goût et Atmosphère. Paris, PUF.

THIBAUD, Jean-Paul (2014) Installing an Atmosphere. In Philip Tidwell (Ed.) Architecture and Atmosphere. Helsinki, Tapio Wirkkala-Rut Bryk Foundation, p. 49-66.

THIBAUD, Jean-Paul (2015) En quête d'ambiances. Eprouver la ville en passant. Genève, MétisPresses.

THIBAUD, Jean-Paul (2017) Towards an Art of Impregnation. In COBUSSEN, Marcel, MEELBERG, Vincent \& TRUAX, Barry (Eds.) The Routledge Companion to Sounding Art. New York, Routledge, p. 265-273.

THORNES, John E. (2008) Cultural climatology and the representation of sky, atmosphere, weather and climate in selected art works of Constable, Monet and Eliasson. Geoforum. 39, p. 570-580.

WHITEHEAD, Alfred North (1920) The Concept of Nature. Cambridge, Cambridge University Press.

ZIMMER, Alexis (2016) Brouillards toxiques. Vallée de la Meuse, 1930, contre-enquête. Zones sensibles. 